\title{
A1619 1968
}
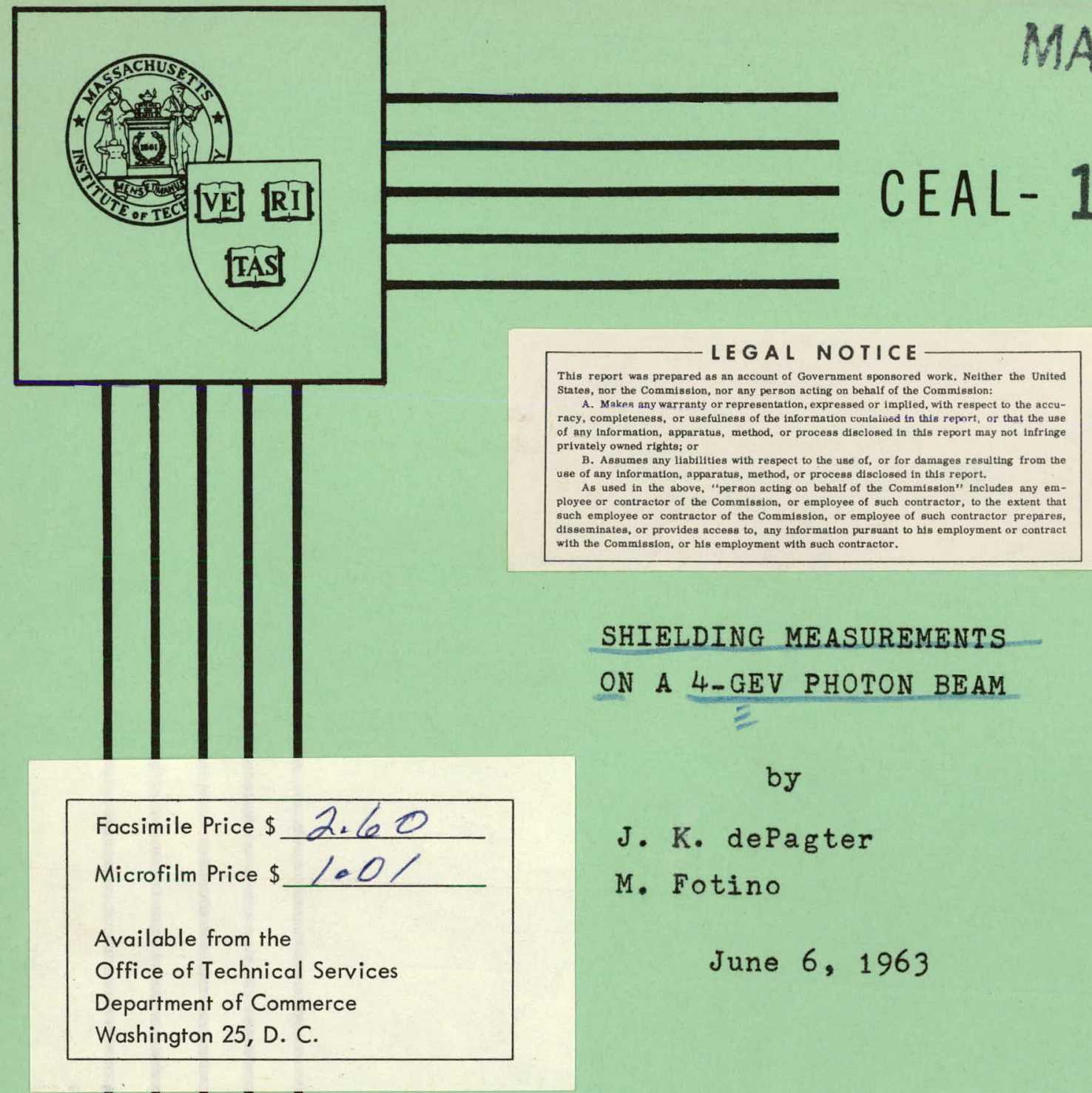

SHIELDING MEASUREMENTS

ON A 4-GEV PHOTON BEAM

by

J. K. dePagter

M. Fotino

$$
\text { June 6, } 1963
$$

\section{MASSACHUSETTS INSTITUTE OF TECHNOLOGY and HARVARD UNIVERSITY}

\section{CAMBRIDGE ELECTRON ACCELERATOR}

CAMBRIDGE 38, MASSACHUSETTS

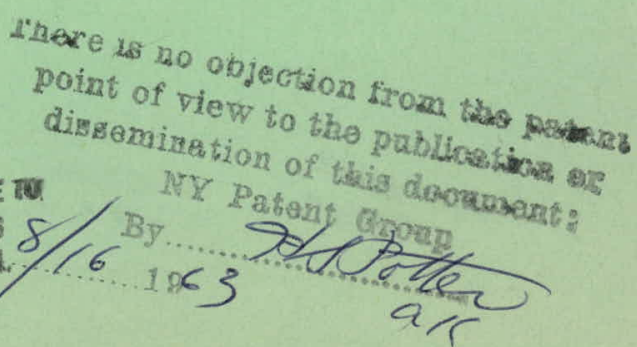

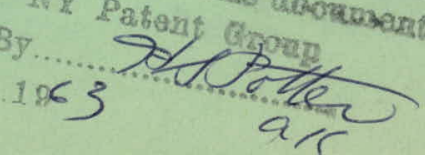

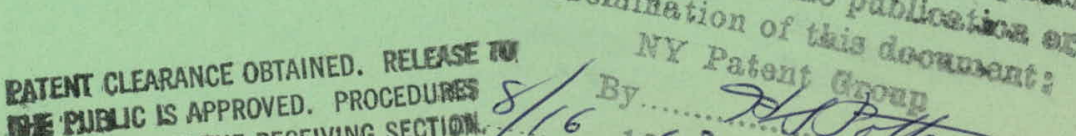

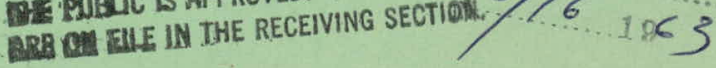




\section{DISCLAIMER}

This report was prepared as an account of work sponsored by an agency of the United States Government. Neither the United States Government nor any agency Thereof, nor any of their employees, makes any warranty, express or implied, or assumes any legal liability or responsibility for the accuracy, completeness, or usefulness of any information, apparatus, product, or process disclosed, or represents that its use would not infringe privately owned rights. Reference herein to any specific commercial product, process, or service by trade name, trademark, manufacturer, or otherwise does not necessarily constitute or imply its endorsement, recommendation, or favoring by the United States Government or any agency thereof. The views and opinions of authors expressed herein do not necessarily state or reflect those of the United States Government or any agency thereof. 


\section{DISCLAIMER}

Portions of this document may be illegible in electronic image products. Images are produced from the best available original document. 


\title{
CAMBRIDGE ELECTRON ACCELERATOR
}

\author{
HARVARD UNIVERSI'YY \\ 42 OXFORD STREET
}

CAMBRIDGE 38, MASS.

\author{
CEAL -1004 \\ James $R$. DePagter \\ Mircea Fotino \\ June 6,1963
}

\section{SHIEIDING MBASUREMENTS ON A 4-GEV PEOTON BEAM}

\begin{abstract}
Results are given for the angular and longitudinal distributions of radiation intensities transmitted through shielding walls in directions parallel and perpendicular to a collimated 4-Gev photon beam. The main exponential attenuation coefficients obtained for ilmenite-loaded concrete $(p: 4,0)$ are: (i) transverse (at $\left.\theta=70^{\circ}\right)$ - nucleonic shower: $\lambda=2.1 / f t$; (ii) longitudinal $\left(0<0<10^{\circ}\right)$ - nucleonic shower $(2<t<6 \mathrm{ft}) \lambda_{n}=1.5 / \mathrm{ft}$; muons $(t>8 \mathrm{ft}) \lambda_{\mu}=0.35 / \mathrm{ft}$. Soft shower penetration: $6 \mathrm{ft}$. An attempt is made to analyze the nature of the transmitted radiation.
\end{abstract}




\section{SHIBLDING MBASURBMBNTS ON A ;-GEV PHOTON BBAM}

\section{INTRODUCTION}

The present measurements were performed at the CBA during September, 1962, shortly after the synchrotron started normal operation. They are intended to provide approximate information about the shielding requirements when multi-Gev photon beams are brought into the Experimental Ha11. The limited scope of the experiment as well as the uncertain performance of the accelerator during its initial stages of operation do not allow a detailed study of various processes involved in the interaction of high-energy photons with matter. As attenuator, only iron-loaded concrete was used.. The energy of the circulating electrons was set at 4 Gev, the highest level of stable operation then available. The average intensity of the circulating beam was about $10^{20}$ electrons/pulse. An internal tungsten wire target $\left(0.1 \mathrm{x}_{0}\right.$ or $0.013^{\prime \prime}$ diameter)* produced a photon beam of about $5 \times 10^{\circ}$ eq. quanta/sec after collimation. This photon beam emerged from the accelerator doughnut through a thin window $\left(0.0015^{\prime \prime}\right.$ stainless stee1) at the end of the exit spout of an ejection vacuum chamber. It was subsequent1y collimated; it was also cleaned of charged secondaries by a 6-ft 1ong, 12,000 gauss clearing magnet before reaching the Experimental Hall via a 4" diameter, 16 ft long hole in the main shielding wall. The entire path of the beam outside the synchrotron (see

* $x_{0}$ represents one radiation length. 
Fig 1) was contained in a vacuum pipe ( $31 / 2^{\text {" diameter. }}$ two $0.0015^{\prime \prime}$ stainless stee 1 windows, $10^{-4} \mathrm{~mm}$ pressure). After emerging from the vacuum pipe the beam was about $1^{\text {" in }}$ diame te $r$.

In the Experimental Ha11, the beam entered a hut made of standard CEA shielding blocks. These were made of concrete loaded with ilmenite $\left(\right.$ Feotio ${ }_{2}$ ) and had a density $p=4.0$, i.e.., $2401 \mathrm{bs} / \mathrm{ft}^{3}$. The typical wal1 thickness was $8 \mathrm{ft}$. A 4-ft roof was incorporated in order to eliminate any substantial contribution from sky-shine.

The beam monitor consisted of a thin ionization chamber (1 1/2" aperture) filled with a $95 \%$ Argon $-5 \% \mathrm{CO}_{2}$ mixture at $250 \mathrm{~mm} \mathrm{Hg}$ pressure and calibrated against a Wilson-type quantameter which in turn had previously been compared to the Cornell quantameter.

The radiation detectors consisted of several tissueequivalent ionization chambers designed for use in the CBA radiation safety monitoring system. These chambers have cylindrical symmetry and a re composed essential1y of an aluminum cylindrical she11 ( $1 / 32$ " wall thickness, 8 9/16" diameter, $243 / 8$ " long) with a hydrogenous lining on the inside ( $1 / 8 "$ polyethylene) and surrounded by an outside stainless steel tank (1/16" wa11 thickness, $91 / 4$ " diameter, $261 / 16^{n}$ long). The tank is insulated from the cylinder by rubber spacers and lucite rings. A $1 / 4^{n}$ diameter stainless 
steel collecting electrode is inserted along the axis from one end. The available volume of about 20 liters is filled with methane to 2 atm absolute. Measurements were made for two directions of attenuated radiation: (i) at right angles to the beam ("transverse shielding"), and (ii) along the beam ("longitudinal shielding"). A11 results were normalized for a beam intensity of $10^{1 !}$ eq. quanta/sec. and for detector positions on a Iine paralle1 to and $10 \mathrm{ft}$. away from the beam.

\section{TRANS VERSE SHIELDING}

From the point of view of transverse shielding, any object placed in a photon beam represents in effect a target of finite thickness. For a given incident beam the general outcome of interaction with a target depends on the target thickness. We therefore distinguish between two categories of target thickness: thin $\left(0\right.$ to $\left.0.5 \mathrm{x}_{0}\right)=$ ad thick $\left(>x_{0}\right)$. It is then necessary to determine in each case the amount of shielding required for reducing the outside radiation to tolerable levels.

In this series of measurements the above conditions were approximated by allowing the beam to strike a thin or thick target inside the shielding hut. One side of this hut included a 16-ft long section composed of several 2-ft thick slabs, parallel to the beam, for varying the wall thickness. 
The angular distribution of the attenuated intensity was determined for angles ranging from $35^{\circ}$ to $145^{\circ}$ from the beam direction and for wall thicknesses between 0 and $4 \mathrm{ft}$. A thick target (2" $\mathrm{Pb}$ or $10 \mathrm{X}_{0}$ ) or a thin target $\left(0.25 " \mathrm{Cu}\right.$ or $\left.0.5 \mathrm{x}_{0}\right)$ was placed in one of two positions (A or B in Fig. 2) about 12 ft apart so that either backward or forward angles could be measured. The ion chamber was placed at successive positions along a line parallel to the beam and 11 ft from it.

The curves in Fig 3 summarize the normalized data, after background subtraction, for a thick target ( $\left.>x_{0}\right)$. Meaningful values above background for the arailable beam intensity were obtained with a shielding thickness of up to $4 \mathrm{ft}$. Because most of the shower occurs in the first 4 to 6 radiation lengths, the target thickness in excess of, say, $10 x_{0}$ has only little effect on the intensity of the attenuated radiation. The total intensity measured $I_{\text {Thick }}\left(E_{0}, I_{0}, d_{0}\right)$ is essentially a function of the energy and intensity of the primary beam as well as the distance from the target. For any primary beam of energy $B$ and intensity I at a distance d from the direction of the beam, the intensity of attenuated radiation is given by:

$$
I_{T h i c k}(E, I, d)=2.5 \times 10^{-10} \frac{E Q}{d^{2}} I_{T h i c k}\left(E_{0}, I_{0}, d_{0}\right)
$$

where $E$ is in Gev, I in equivalent quanta per second and $d$ in $f t$. 
These curves show that the maximum intensity occurs at an angle $\theta=70$ to $80^{\circ}$ from the primary direction.

The values for angles of about $90^{\circ}$ appear lower than would be suggested by the rest of the curve. This reflects the fact that the target width ( $4^{\prime \prime} \vec{P} b$ ) was such that considerable self-absorption of the secondary radiation would take place in the target.

For a thin target ( 0 to $0.5 x_{0}$ ) the situation is different. Here we have to deal only with the initial stages of showe $r$ development and to a good approximation the number of electrons and photons increases more or less exponentially with target thickness. The measurements for this case were made with a maximum intensity of only $2 f t$. of concrete in order to keep the values significantly above background. The results are shown in Fig 4. They were normalized, as in the previous case, for $I_{0}=10^{11}$ eq. quanta/sec., for a target thickness of $x_{0}$ and for detector positions on a line parallel to the beam and $\mathrm{d}_{0}=10 \mathrm{ft}$. away. For any primary beam intensity $I$, target thickness $x$ and distance d from the beam line, the transmitted radiation intensity $I_{\text {thin }}(I, d, x)$ may be approximately obtained from the relation:

$$
I_{\operatorname{thin}}(I, d, x)=10^{-9} \frac{I}{d^{2}}\left(e^{\frac{x}{X_{0}}}-1\right) I_{\operatorname{thin}}\left(I_{0}, d_{0}, x_{0}\right)
$$

whe re again $I$ is in eq. quanta/sec., $d$ in $f t ., x$ in rad. lengths $x_{0}$ 
As in the case of a thick target, the maximum radiation outside the shielding wall does not occur in a direction of minimum thickness $\left(90^{\circ}\right)$, but for a forward angle of about $60^{\circ}$ to $70^{\circ}$ from the primary beam. The width at half-maximum $\left(\sim 74^{\circ}\right)$ of the angular distribution is slight1y larger than for that $\left(\sim 66^{\circ}\right)$ obtained using a thick target and the same shielding thickness. Furthermore the tail end of the curve at large angles indicates that back-scattering is more important when a thin target is used.

From these results we can infer that the attenuation of transmitted intensity follows approximately an exponential law of the form $e^{-\lambda t}$. At $\theta=70^{\circ}$, the attenuation coefficients are $\lambda_{0-2}=2.4 / f t$. for wall thicknesses between 0 and $2 \mathrm{ft}$. and $\lambda_{2-4}=1.8 / \mathrm{ft}$. for wall thicknesses between 2 and $4 \mathrm{ft}$. It is reasonable to assume that the radiation in this case is due to the nucleonic shower since the lateral extent of a soft shower would be much smaller.

It was not possible under the circumstances to study in detail the nature of the radiation outside the shielding wa11. However, a crude analysis was made in the case of a 6-ft. wall by means of (i) a portable $\mathrm{BF}_{3}$ survey meter (Nemo, Type 2715) sensitive to fast neutrons only (recently calibrated to $\pm 15 \%$ for 1 to 4 Mev neutrons against a Pu-Be source) and (ii) an air-filled portable beta-gamma ionization chamber (Ekco Type 555). This 1atter detector was found to have sensitivities ( $\eta_{i c}$ ) to neutrons and ( $y_{i c}$ ) to $y$-rays in 
the same ratio as the non-tissue-equivalent ion chamber discussed in Part IV, name1y:

$$
\frac{V_{i c}}{\eta_{i c}}=6.1 \text { and therefore: } I_{i c}=I_{\gamma}+\frac{1}{6.1} I_{n}
$$

where $I_{i c}$ is the reading of the ionization chamber.

The neutron intensity $I_{n}$ in millirads per hour (mr/hr) was measured with the $\mathrm{BF}_{3}$ survey meter to be $20 \%$ of $\mathrm{I}_{\text {ic }}$ :

$$
I_{n}=0.2 I_{i c}
$$

Therefore the $\gamma$-ray intensity is given by:

$$
I_{\gamma}=I_{i c}-\frac{0.2}{6.1} I_{i c}=0.97 I_{i c}
$$

And the total intensity is:

$$
I=I_{\gamma}+I_{n}=1.17 I_{i c},
$$

we obtain the following relative intensities:

$$
\begin{aligned}
& I_{n}=0.17 I \\
& I_{Y}=0.83 I
\end{aligned}
$$

If now we conservatively assume $\mathrm{RBE}=10$ (corresponding to 1 Mev neutrons), the total intensity of interest for biological considerations (in rem/hr) is then:

$$
I_{b i 01}=I_{\gamma}+10 I_{n}=2.53 I
$$

It is therefore acceptable to adopt, as an approximate upper 1 imit, the value $R B E=3$ for the radiation traversing the shielding wall, particularly in view of the fact that 
the electromagnetic component (for which $R B E=1$ ) has a smaller attenuation length than neutrons.

\section{LONGITUDINAL SHIELDING}

The second series of measurements covered both the longitudinal attenuation with thickness and lateral angular spread of the radiation downstream from a shielding wall perpendicular to the beam. For this purpose the experimental setup was modified as shown in Fig 5 .

Angular distributions covered the range from $0^{\circ}$ to $20^{\circ}$. The wall thickness was varied from 2 to $12 \mathrm{ft}$. A 2" thick $\mathrm{Pb}$ absorber was placed in positions $A, B$, and $C$ 4 ft. apart from each other. This absorber is sufficient to eliminate most of the soft shower component. When used, it was taken as the source for the angular distribution. When the absorber was left out, the radiation source was distributed over a fairly large volume and accordingly the origin for the angular distribution was taken to be located about $1 \mathrm{ft}$. inside the concrete block and downstream from the front surface of the wall. This corresponds approximately to the position of the shower maximum inside the concrete.

The angular spread of the transmitted radiation with no absorber is shown in Fig 6 and the corresponding longitudinal attenuation at various angles in Fig 7 . The results were again normalized for a beam intensity $10^{11}$ eq. quanta/sec. 
Two different regions can be distinguished in the at tenuation curves:

(i) Wall thickness 2 to $6 \mathrm{ft} .\left(12-36 \mathrm{x}_{0}\right)$. The attenuation matches closely that of a soft shower of several Gev as determined from shower theory (e.g. B. Rossi, High Bnergy Particles, p. 261). Without making a detailed analysis of the influence of the bremsstrahlung spectrum on the attenuation behavior, one can say that the slope of the resulting soft ohower tail (dominant in the region 4 to 6 $f t$.$) is the same as that resulting from a monochromatic$ primary 4 Gev photon beam (see Fig 7).

(ii) Wall thickness 6 to $12 \mathrm{ft} \cdot\left(36-72 \mathrm{x}_{0}\right)$. The dominant component consists of muons since the nucleonic component would be attenuated by an order of magnitude more rapidiy than the observed attenuation rate,

In another series of measurements, the $P b$ absorber was placed against the shielding wall (position $A$ in Fig 5). The lateral angular spread and the corresponding longitudinal attenuation of the transmitted radiation are shown in Figures 8 and 9 respectively. As in the previous case (no absorber), two different regions are clearly distinguished:

(1) Wall thickness 2 to $6 \mathrm{ft} .\left(12-36 \mathrm{x}_{0}\right)$. The nucleonic component is dominant with an attenuation length $I_{n}=8$ in.

(ii) Wa11 thickness 6 to $12 \mathrm{ft} .\left(36-72 \mathrm{x}_{0}\right)$. The muon component is again dominant as in the corresponding no-absorber case. 
It is interesting to note that the knee of the attenuation curves for both cases (with and without absorber) occurs at about the same penetration depth (in $\left.g / \mathrm{cm}^{2}\right)$. For small penetration depths (below the knee) the Pb absorber, by its effectiveness in attenuating the soft component, reduces the transmitted intensity by an additional factor of 20 to 30 , while for large penetration depths (above the knee) the reduction due to the $P b$ absorber is an order of magnitude smaller and uniform over the whole range.

Another set of measurements was performed with the same geometry (Fig 5) in order to determine the effect of placing the $P b$ absorber upstream from the shielding wall in positions $A, B$, and $C$. The results for a 6-ft. wall are chown in Fig 10 .

In each case it was necessary to average the area under the curve up to $10^{\circ}$ from beam direction in order to overcome the difficulty that the detector width is comparable to the half-width of the distribution. If the transmitted radiation were only muons produced in the $\mathrm{Pb}$ absorber, it is reasonable to expect the intensity to be proportional to the solid angle subtended by the detector at the source. The ratios of intensities for the $P b$ absorber in positions $A, B$, and $C$ would then be $1: 0.6: 0.4$ respectively. The actual measured intensities were approximately $1: 0.85: 0.7$. This discrepancy is to be accounted for by penetrating muons coming essentially from the decay in flight of pions produced in the Pb absorber. 
Focusing our attention on the pion and muon components only, we can use the data obtained with the absorber in positions $A, B$, and $C$ to determine: (i) the relative importance of pion decay in the radiation penetrating large thicknesses of shielding, (ii) the effectiveness of placing the shielding near the pion source in reducing the muon component and (iii) the ratio at production of muons to pions capable of producing penetrating secondaries of comparable range.

Assuming a geometrical cross-section for the removal of pions from the beam, one obtains a geometric mean free path in heavy concrete $\lambda_{g}=0.7 \mathrm{~m}$ or $2.3 \mathrm{ft}$. At $1.5 \mathrm{Gev}$, which is the minimum energy of a pion producing a muon capable of penetrating a 6-ft wall, the mean range for the pion decaying in 1 ight is $90 \mathrm{~m}$ or $295 \mathrm{ft}$. The fraction of decaying pions is then proportional to the flight paths available before removal through interaction with matter. For positions $A, B$, and $C$ these distances are $2.3 \mathrm{ft}, 6.3$ ft and $10.3 \mathrm{ft}$ respectively.

Combining the simple $1 / x^{2}$ dependence with the ratios of $1: 2.7: 4.5$ from flight path differences, we obtain for the ratios of muons produced in pion decay $1: 1.65$ : 1.75. The contributions from muons produced in the $\mathrm{Pb}$ absorber follow the same $1 / r^{2}$ dependence. Therefore the proportions of pion-produced muons $\left(\mu_{\pi}\right)$ to muons produced in the absorber $\left(\mu_{\mu}\right)$ located at positions $A, B$, and C are: 


\begin{tabular}{lc}
$\frac{\mu_{\pi}}{\mu_{\mu}}$ & Position \\
\hline 0.28 & A \\
0.77 & B \\
1.2 & C
\end{tabular}

Finally, we can estimate an upper limit for the same ratio if we assume a flight path long enough so that all pions decay into muons. For a pion energy of, say, 2 Gev the mean flight path before decay is $112 \mathrm{~m}$ and hence the upper $\operatorname{limit}$ is:

$$
\left(\frac{\mu_{\pi}}{\mu_{\mu}}\right)=\left(\frac{\mu_{\max }}{\mu_{\mu}}\right) \frac{112}{\lambda_{g}}=45
$$

Great benefit can be gained, using a shielding wall of given thickness, by placing the wall close to the source. If conversely the source-to-wall distance is large (e.E. if the pion flight path is longer than $10 \mathrm{ft}$ ), the muon component produced directly in the absorber will be enhanced by muons resulting from pion-decay and one expects the level of penetrating radiation to rise with increasing fight path.

\section{SENSITIVITIES}

The y-ray sensitivities of ionization chambers were measured using a $\gamma$-ray source $\left(1.05\right.$ arie of $\left.\mathrm{Co}^{60}\right)$. The measurements were repeated periodically during the experiment. Calibration and sensitivity measuroments were also made using a Pu-Be source of neutrons $\left(8.09 \times 10^{6} \mathrm{n} / \mathrm{sec}\right)$ at the 
Harvard University School of Public Health. Of the two ion chambers thus calibrated, one (IC-15) had the tissueequivalent structure described above and the other (IC-1) had no hydrogenous lining and was filled with nitrogen. The chambers were situated at a distance of $1 \mathrm{~m}$ from the source. We define:

$$
\begin{aligned}
\eta & =\text { neutron sensitivity of } \mathrm{IC}-1 \\
\eta_{\mathrm{te}} & =\text { neutron sensitivity of } \mathrm{IC}-15 \\
\gamma & =\gamma \text {-ray sensitivity of } \mathrm{IC}-1 \\
\gamma_{\mathrm{te}} & =\gamma \text {-ray sensitivity of IC-15 } \\
\text { Using a } & \text { Co }{ }^{60} \text { source, we found the following values: } \\
\gamma & =3.35 \times 10^{-7} \mathrm{a} /(\mathrm{mr} / \mathrm{hr}) \\
\gamma_{t e} & =2.70 \times 10^{-7} \mathrm{a} /(\mathrm{mr} / \mathrm{hr})
\end{aligned}
$$

The measurements of $\eta$ were made with and without a $2^{\prime \prime}-t h i c k$ Pb shield surrounding the neutron source, the purpose of the shield being to filter out the $y$-ray component of the source and thus determine the neutron sensitivity. The measured values of the ion chamber currents were:

$$
\begin{array}{llrl}
\text { IC-15 without shield } & i_{t e}=3.35 \times 10^{-7} \mathrm{a} \\
\text { IC-15 with 2" Pb shie1d } & i_{t e}^{\prime}=3.15 \times 10^{-7} \mathrm{a} \\
\text { IC-1 without shie1d } & i=1.7 \times 10^{-7} \mathrm{a} \\
\text { IC-1 with 2" Pb shield } & i^{\prime}=0.8 \times 10^{-7} \mathrm{a}
\end{array}
$$

If we let

$$
\begin{aligned}
& \Phi_{n}=\text { neutron flux at } 1 \text { m from source without shield } \\
& \Phi_{\gamma}=\gamma \text {-ray flux at } 1 \text { m from source without shield } \\
& \Phi_{n}^{\prime}=\text { neutron flux at } 1 \mathrm{~m} \text { from source with shield } \\
& \Phi_{Y}^{\prime}=\gamma \text {-ray flux at } 1 \mathrm{~m} \text { from source with shield }
\end{aligned}
$$


then:

$$
\begin{aligned}
& \eta_{t e} \Phi_{n}+\gamma_{t e} \Phi_{\gamma}=i_{t e} \\
& \eta_{t e}{ }_{n}+\gamma_{t e}{ }_{Y}^{\nu}=i_{\text {te }} \\
& \eta \Phi_{n}+\gamma_{\gamma}^{\sigma}=i \\
& \eta_{n}^{\prime}+Y \Phi_{Y}^{\prime}=i^{\prime}
\end{aligned}
$$

From the known source strength:

$$
\Phi_{\mathrm{n}}=64.5 \mathrm{n} /\left(\mathrm{cm}^{2} \mathrm{sec}\right) \text { or } 1 \mathrm{mr} / \mathrm{hr} \ldots
$$

and solving the above equations for $\Phi_{n}^{\prime} / \Phi_{n}$ we obtain:

$$
\Phi_{n}^{*} / \Phi_{n}=1.27 \text { or } \Phi_{n}^{\prime}=81.9 \mathrm{n} /\left(\mathrm{cm}^{2} \mathrm{sec}\right)
$$

We should remark at this point that the pu-Be source was mounted on the flat end of a $2^{\text {r }}$ dia parafin rod. The rod was held horizontally pointing toward the ion chamber in the $\mathrm{Pb}$ shielding case and vertically in the other. When the rod was pointed toward the ion chamber (i.e. the source viewed norma11y to its surface), the anisotropy due to backscattering from the parafin results in an increase of the neutron flux as compared to that observed when the source is viewed tangentially. The above value of $\Phi_{n} / \Phi_{n}$ is compatible with these circumstances.

Upper and lower limits for the neutron sensitivity $\eta_{\text {te }}$ of the tissue-equivalent ion chamber can readily be obtained. If we assume that the lead shielding absorbs al1 the $y-r a y s$ from the source, then ${ }_{\gamma}^{*}=0$ and hence:

$$
\begin{aligned}
& \eta^{\max }=0.63 \times 10^{-7} \mathrm{a} /(\mathrm{mr} / \mathrm{hr}) \\
& \eta_{t e}^{\max }=2.48 \times 10^{-7} \mathrm{a} /(\mathrm{mr} / \mathrm{hr})
\end{aligned}
$$


In order to obtain a lower limit for these sensitivities we assume the non-tissue-equivalent ion chamber to be insensitive to neutrons, $\eta^{\min }=0$, and thus:

$$
\eta_{\text {te }}^{\mathrm{min}}=1.97 \times 10^{-7} \mathrm{a} /(\mathrm{mr} / \mathrm{hr})
$$

These limits clearly do not correspond to the actual conditions. A more realistic estimate of $\eta_{\text {te }}$ is obtained by calculating the attenuation in the $2^{\prime \prime}$-thick Pb shield of the principal component of the $y$-ray flux, i.e. the 4.3 Mev $y$-ray and neglecting the 7 Mev and 2.6 Mev contributions. The transmitted intensity is then:

$$
\Phi={ }_{Y}^{B}{ }_{Y}^{B} e^{-\mu x}
$$

where $B_{r}=1.7$ is the buildup factor for 4 Mev y-rays proceeding from a point source and traversing a $2^{\prime \prime-}$-thick $\mathrm{Pb}$ absorber $\left(x=56.5 \mathrm{~g} / \mathrm{cm}^{2}\right)$ for which $\mu=0.042 \mathrm{~cm}^{2} / \mathrm{g}$. Hence:

$$
\Phi_{Y}^{P}=0.16 \Phi_{Y}
$$

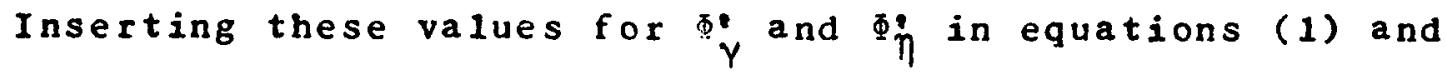
(2) and solving for $\eta_{\text {te }}$ we obtain:

$$
\eta_{\text {te }}=2.36 \times 10^{-7} \mathrm{a} /(\mathrm{mr} / \mathrm{hr})
$$

It is thus clear that IC-15 appears to be close to an ideal tissue-equivalent chamber since its sensitivity to neutrons $\eta_{\text {te }}$ is only about $12 \%$ smaller than its sensitivity to $\gamma$-rays $\gamma_{\text {te }}$. For an ideal tissue-equivalent ion chamber these sensitivities would, of course, be equal. 
It is interesting to compare in the same fashion the sensitivities of a non-tissue-equivalent ion chamber ( IC-1, which has no hydrogenous lining). Using the same estimate as above for $\eta_{\text {te }}$ we obtain from equation (1):

$$
\Phi_{\gamma}=0.37 \mathrm{mr} / \mathrm{hr}
$$

and from equation ( 3 ):

$$
\eta=0.55 \times 10^{-7} \mathrm{a} /(\mathrm{mr} / \mathrm{hr})
$$

The ratio of interest for this chamber is then:

$$
\frac{y}{\eta}=6.1
$$

indicating substantial departure from tissue-equivalence.

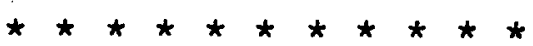

Because of large uncertainties in the performance of the quantameter and the monitoring ion chamber and in the calibration of the two ion chambers, the accuracy of the present data is estimated to be no better than 15-20\% for radiation levels substantially above background.

We wish to acknowledge our indebtedness to Prof. M. S. Livingston, who did most of the initial planning for this experiment. His continued interest in this project was essential to its completion. The wholehearted cooperation of the CBA Operations Division is also most gratefu11y acknowledged. 


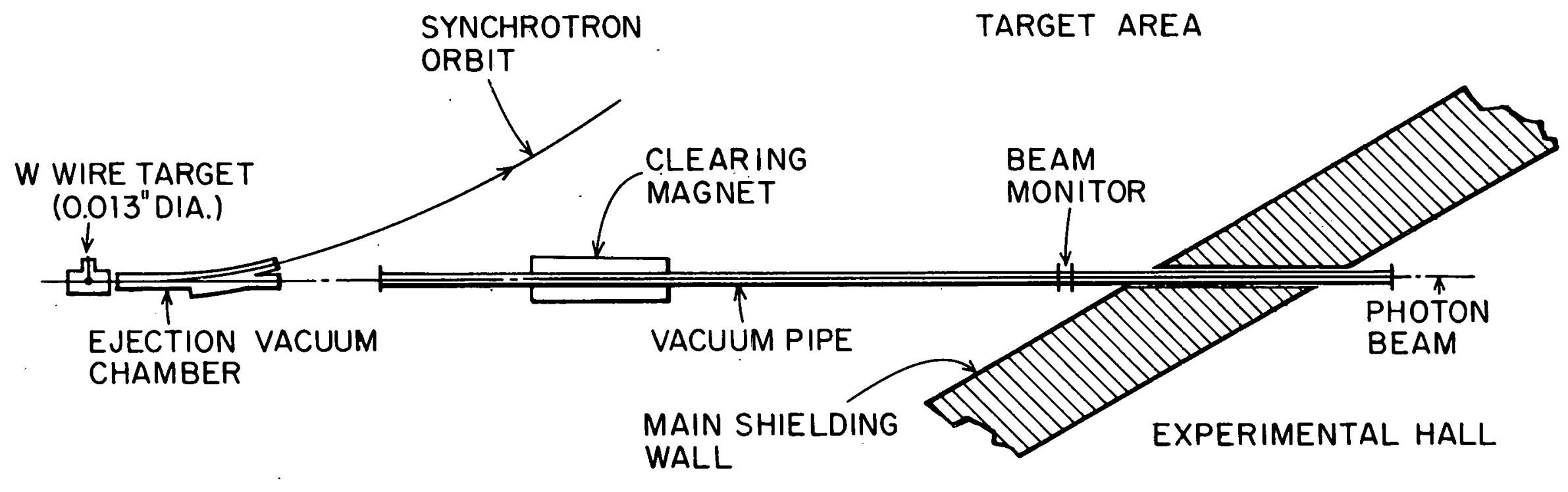

(NOT TO SCALE)

FIG. I LAYOUT OF THE PHOTON BEAM 


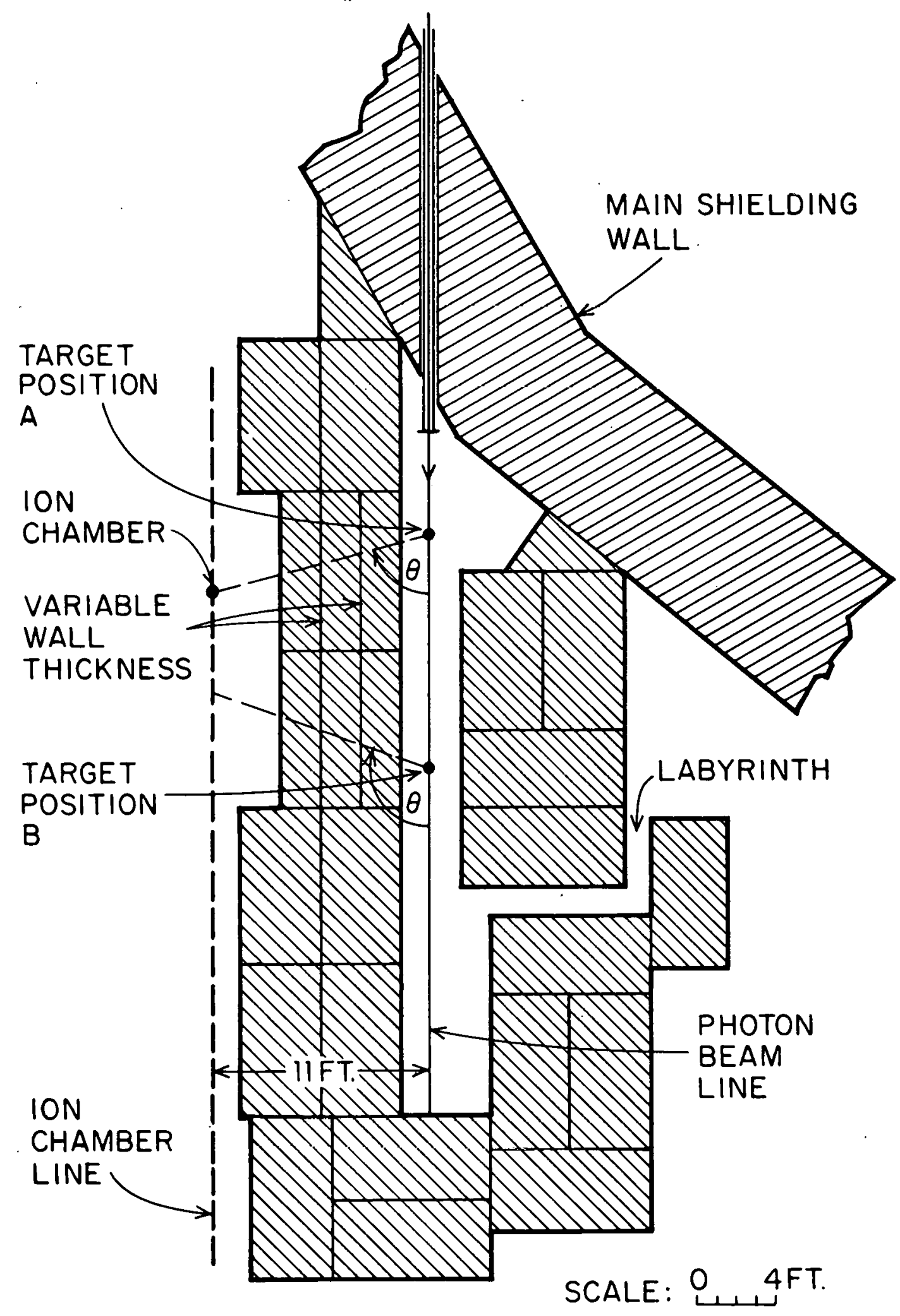

FIG. 2 EXPERIMENTAL SETUP FOR TRANSVERSE SHIELDING 
$I_{\text {Thick }}\left(E_{0}, I_{0}, d_{0}\right)$

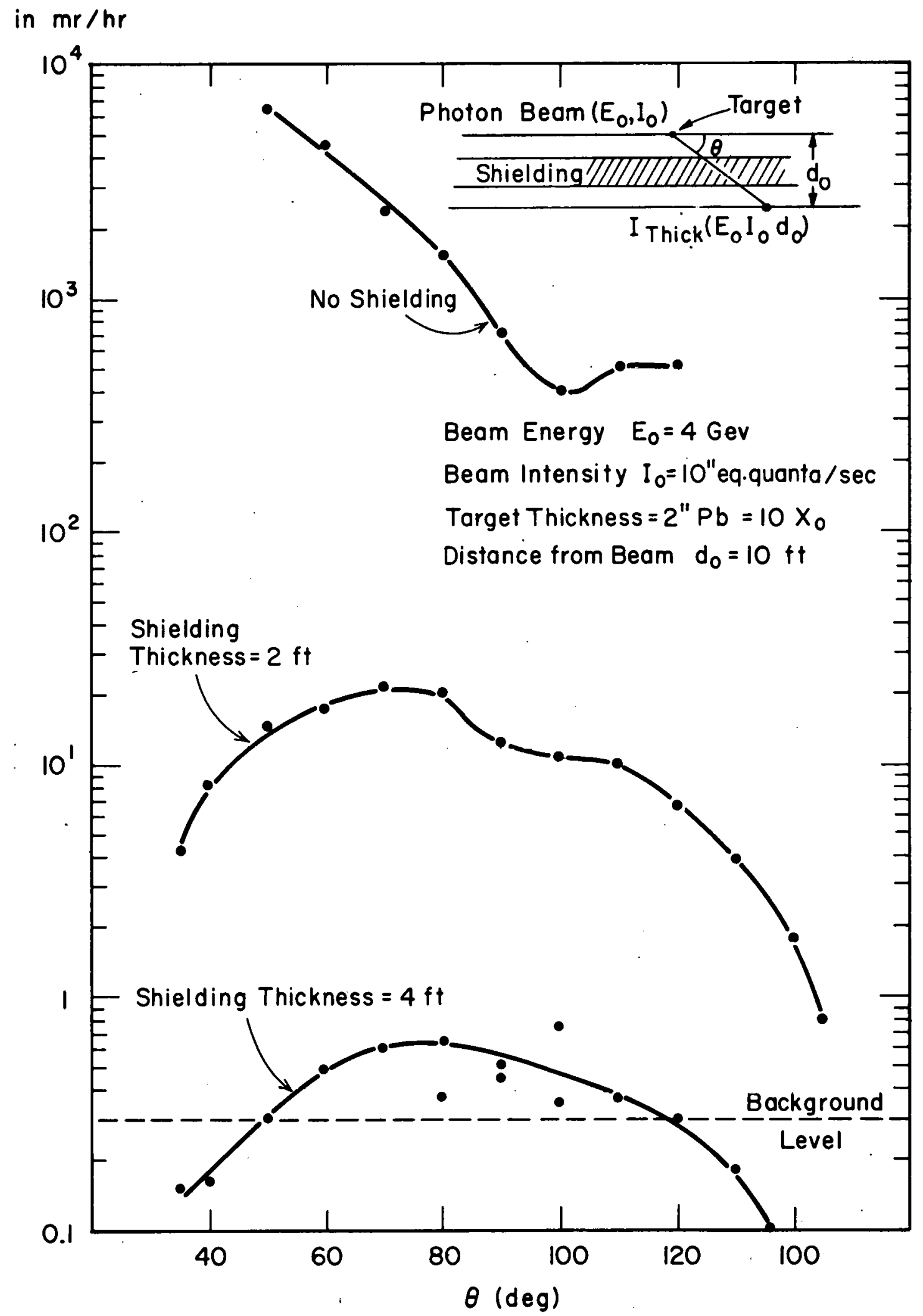

FIG. 3 TRANSVERSE SHIELDING - ANGULAR DISTRIBUTION OF RADIATION INTENSITY I Thick $\left(E_{0}, I_{0}, d_{0}\right)$ FROM THICK TARGET $\left(10 x_{0}\right)$. 
$I_{\text {thin }}\left(I_{0}, d_{0}, X_{0}\right)$

in $\mathrm{mr} / \mathrm{hr} \mathrm{X}_{0}$

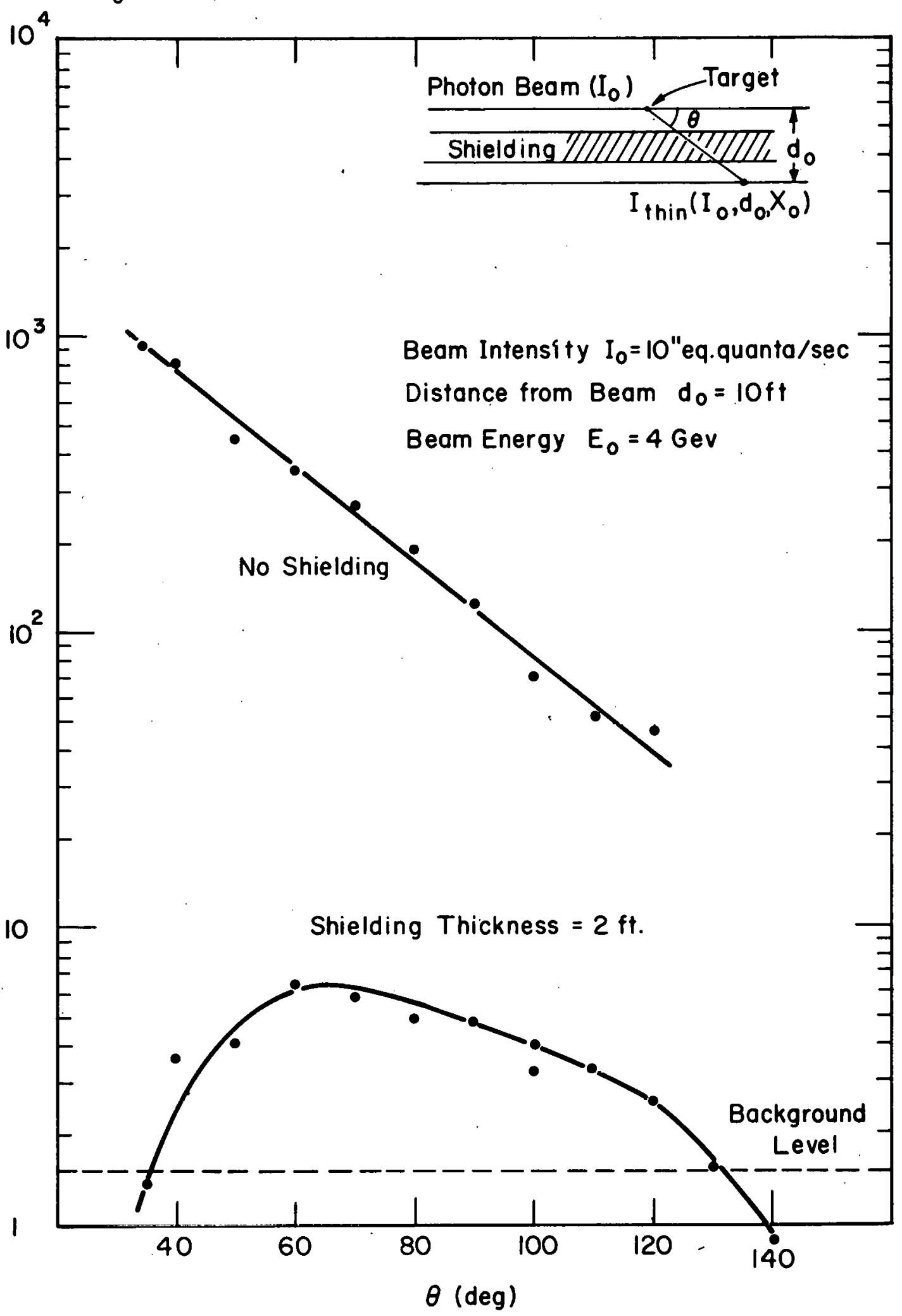

FIG. 4 TRANSVERSE SHIELDING - ANGULAR DISTRIBUTION OF RADIATION INTENSITY $I_{\text {thin }}\left(I_{0}, d_{0}, X_{0}\right)$ PER UNIT $X_{0}$ FROM THIN TARGETS. 


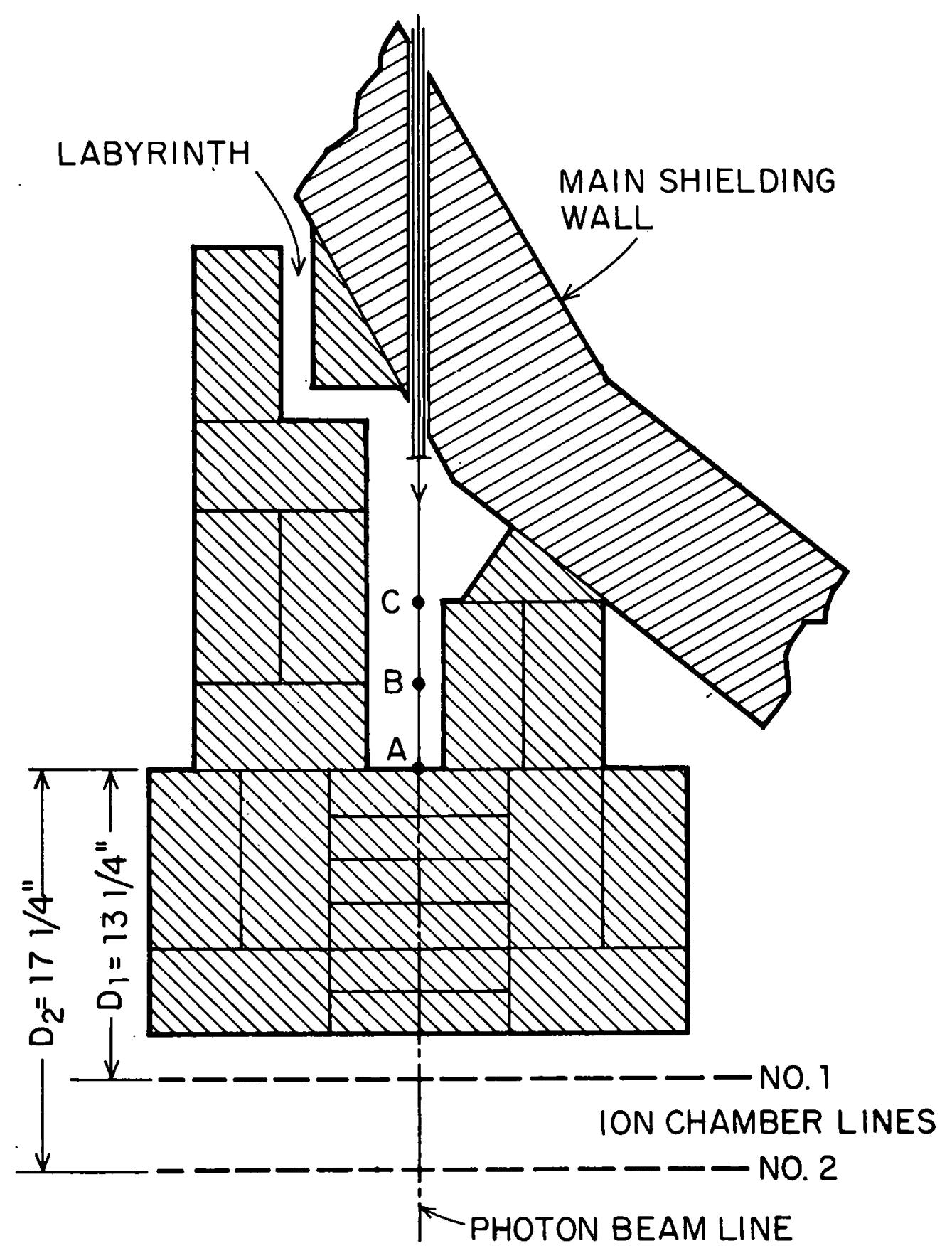
$A, B, C:$ ABSORBER POSITIONS
SCALE: 0 4 4 FT.
FIG. 5 EXPERIMENTAL SETUP FOR LONGITUDINAL SHIELDING 




FIG. 6 LONGITUDINAL SHIELDING - ANGULAR SPREAD OF TRANSMITTED INTENSITY FOR VARIOUS VALUES OF SHIELDING THICKNESS. NO ABSORBER. 


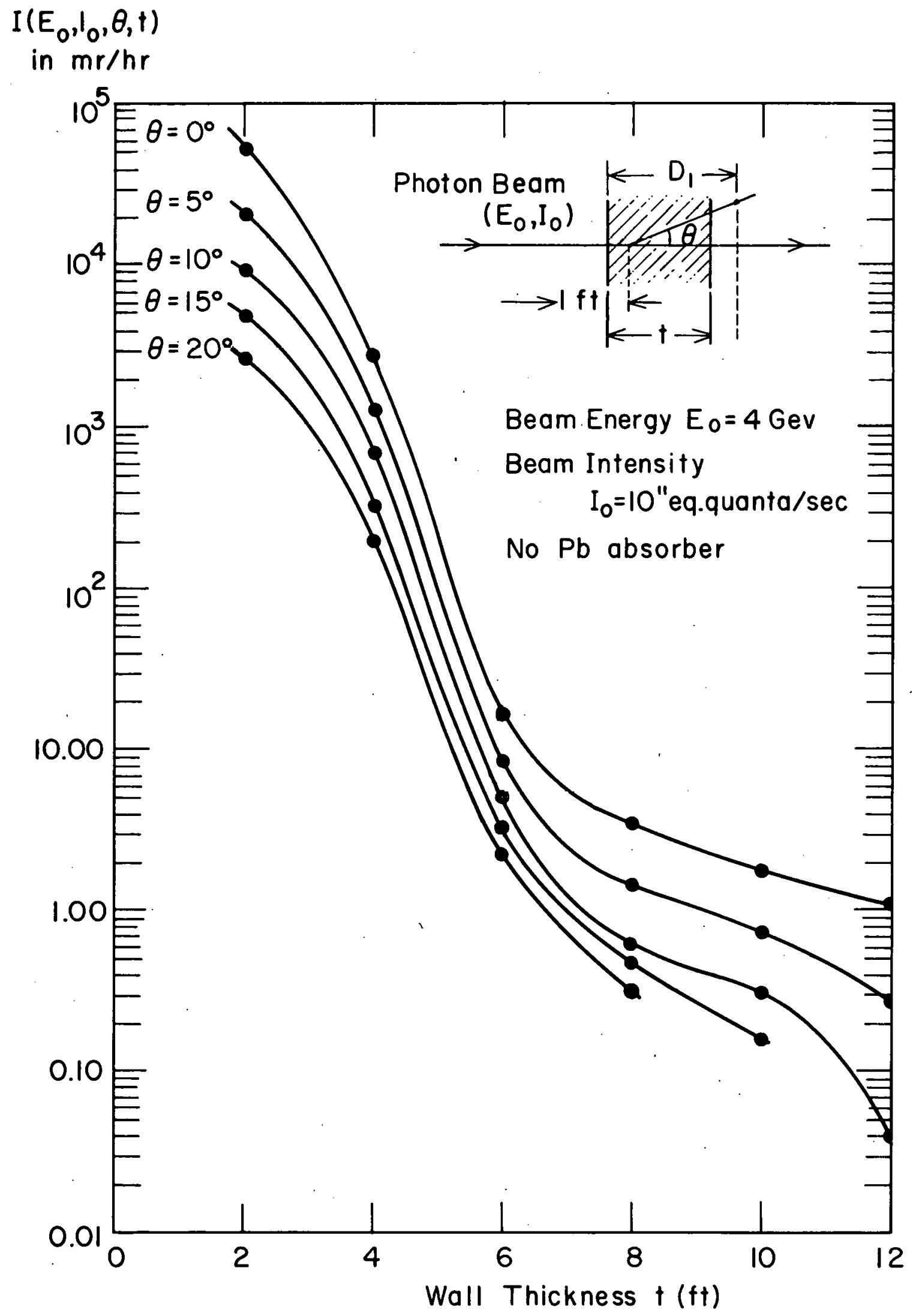

FIG.7 LONGITUDINAL SHIELDING - LONGITUDINAL ATTENUATION OF TRANSMITTED INTENSITY AT VARIOUS ANGLES. NO ABSORBER. 
I $\left(E_{0}, I 0, \theta, t\right)$

in $\mathrm{mr} / \mathrm{hr}$

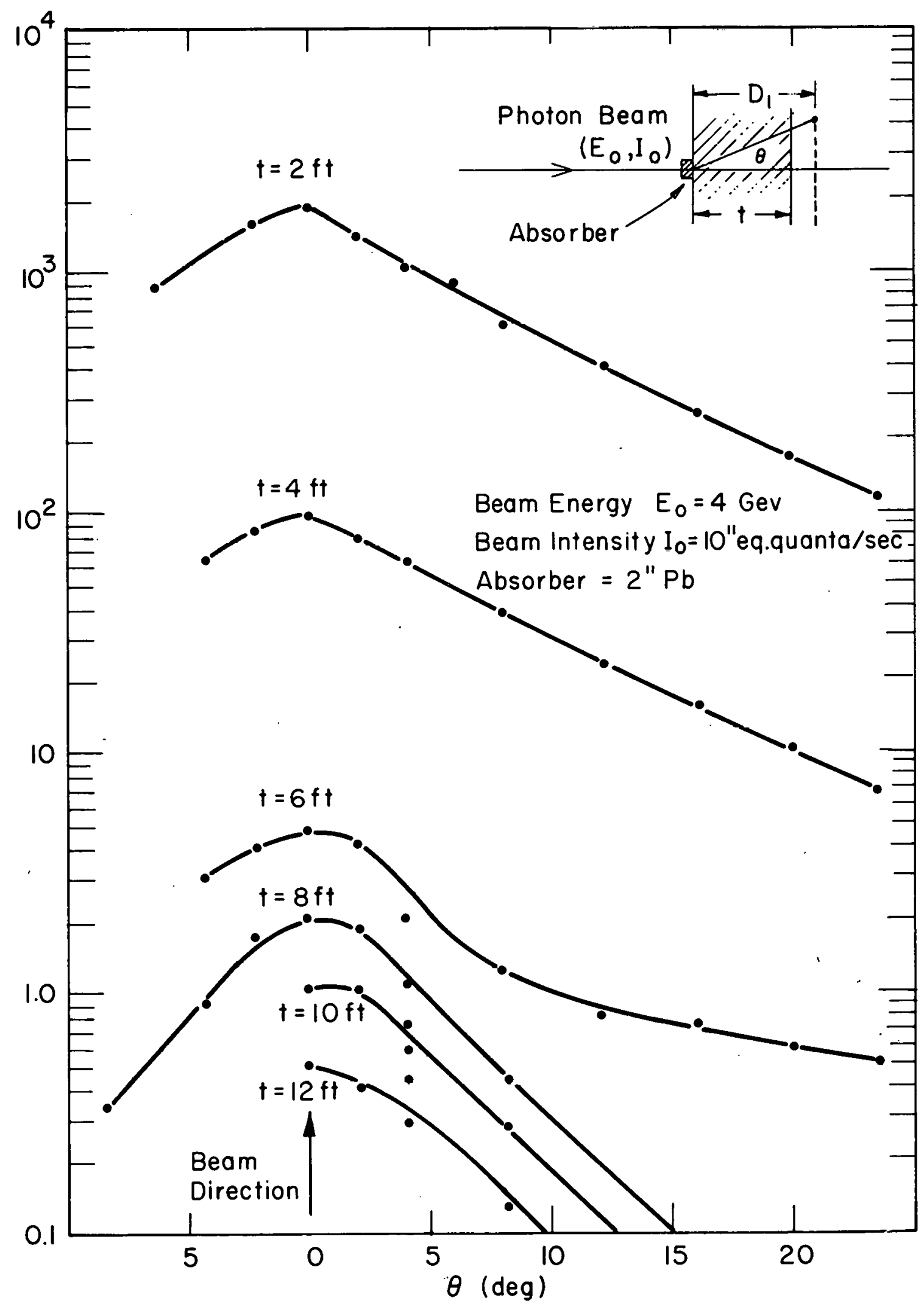

FIG. 8 LONGITUDINAL SHIELDING - ANGULAR SPREAD OF TRANSMITTED INTENSITY FOR VARIOUS VALUES OF SHIELDING THICKNESS. 2" $\mathrm{Pb}$ Absorber. 


\section{$I\left(E_{0}, I_{0}, \theta, t\right)$}

in $\mathrm{mr} / \mathrm{hr}$

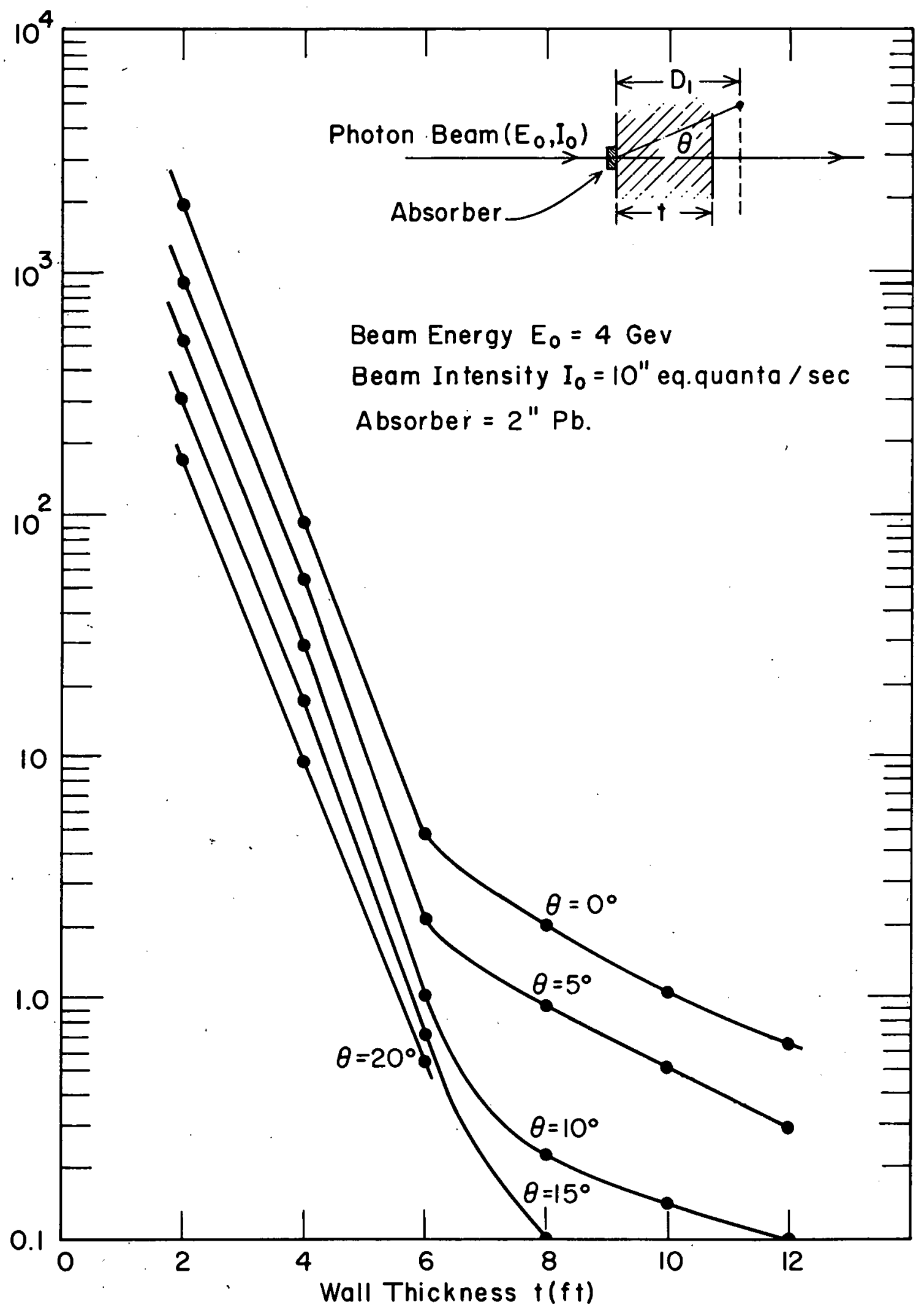

FIG. 9 LONGITUDINAL SHIELDING - LONGITUDINAL ATTENUATION OF TRANSMITTED INTENSITY AT VARIOUS ANGLES. $2 " \mathrm{~Pb}$ ABSORBER. 
Intensity

in $\mathrm{mr} / \mathrm{hr}$

5.0

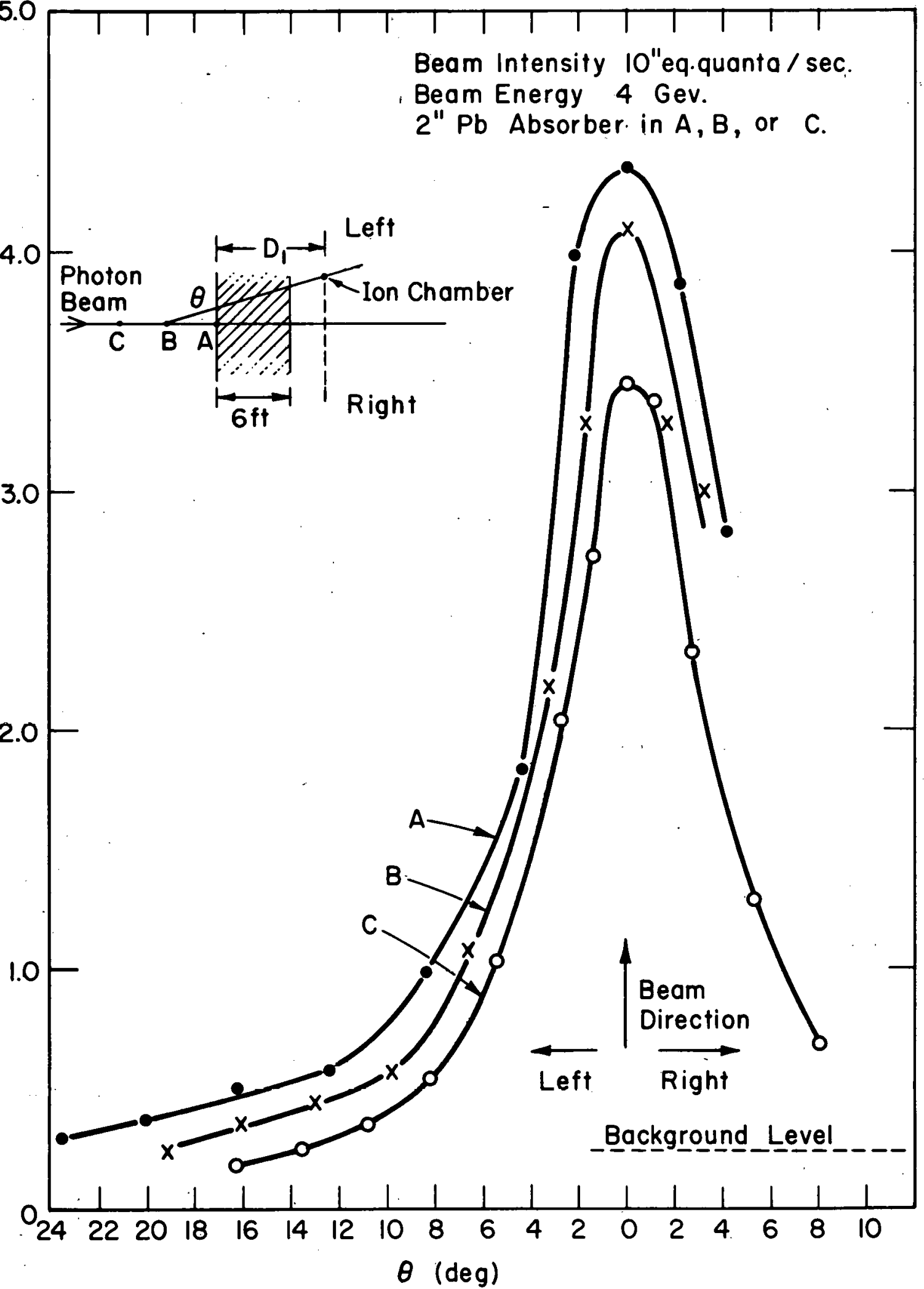

FIG. 10 LONGITUDINAL SHIELDING - ANGULAR DISTRIBUTION OF TRANSMITTED RADIATION INTENSITY WITH 2" Pb ABSORBER IN POSITIONS A,B AND C FOR 6-FT WALL THICKNESS. 
IEGAL NOTICE

This report was prepared as an account of Government sponsored work. Neither the United States, nor the Commission, nor any person acting on behalf of the Commission:

A. Makes any warranty or representation, express or implied, with respect to the accuracy, completeness, or usefulness of the information contained in this report, or that the use of any information, apparatus, method, or process disclosed in this report may not infringe pri.. vately owned rights or

B. Assumes any liabilities with respect to the use of, or for damages resulting from the use of any information, apparatus, method, or process disclosed in this report.

As used in the above, "person acting on behalf of the Commission" includes any employee or contractor of the Commission to the extent that such employee or contractor prepares, handles or distributes, or provides access to any information pursuant to this employment or contract with the Commission. 